\title{
Applications of CRISPR/Cas9 System in Vegetatively Propagated Fruit and Berry Crops
}

\author{
Anastasia Fizikova $1, * \mathbb{C}$, Nadezhda Tikhonova ${ }^{1,2} \mathbb{1}$, Yulia Ukhatova ${ }^{1,2}$, Roman Ivanov ${ }^{1}$ \\ and Elena Khlestkina $1,2, *$ (D) \\ 1 Plant Biology and Biotechnology Department, Sirius University of Science and Technology, Olympic Avenue, \\ 1, 354340 Sochi, Russia; n.g.tikhonova@vir.nw.ru (N.T.); sci_secretary@vir.nw.ru (Y.U.); \\ Ivanov.RA@talantiuspeh.ru (R.I.) \\ 2 N.I. Vavilov All-Russian Research Institute of Plant Genetic Resources (VIR), B. Morskaya Street, 42-44, \\ 190000 St. Petersburg, Russia \\ * Correspondence: Fizikova.AY@talantiuspeh.ru (A.F.); director@vir.nw.ru (E.K.)
}

Citation: Fizikova, A.; Tikhonova, N.; Ukhatova, Y.; Ivanov, R.; Khlestkina, E. Applications of CRISPR/Cas9 System in Vegetatively Propagated Fruit and Berry Crops. Agronomy 2021, 11, 1849. https:// doi.org/10.3390/agronomy11091849

Academic Editors:

Muhammad Amjad Nawaz,

Kirill S. Golokhvast, Gyuhwa Chung, Aristidis M. Tsatsakis

and Michael N. Antoniou

Received: 20 August 2021

Accepted: 13 September 2021

Published: 15 September 2021

Publisher's Note: MDPI stays neutral with regard to jurisdictional claims in published maps and institutional affiliations.

Copyright: (c) 2021 by the authors. Licensee MDPI, Basel, Switzerland. This article is an open access article distributed under the terms and conditions of the Creative Commons Attribution (CC BY) license (https:/ / creativecommons.org/licenses/by/ $4.0 /)$.

\begin{abstract}
Fruit and berry crops, as well as grapes, are important parts of the human diet and, at the same time, significant objects of genetic, breeding, biochemical and nutritional research. Traditional approaches of crop research and improvement are now complemented by effective modern genetic technologies. In this review, we analyze and summarize the achievements in genome editing of fruit, berry crops and grapes. New approaches accelerate the improvement of genotypes for many groups of traits: plant resistance to unfavorable environmental factors, flowering and ripening time, plant architectonics, fruit shelf time and biochemical composition. Genome editing using the CRISPR/Cas9 system has been successfully tested on the most important vegetatively propagated fruit and berry crops (apple, pear, orange, kumquat, grapefruit, banana, strawberry and kiwi) and grapes. About 30 genes of these crops have been used as targets for the introduction of desired mutations using the CRISPR/Cas9 system. The most valuable results are the improvement of important agronomic traits. For 24 genes it has been shown that their knockout can result in the improvement of varieties. In addition, the review pays attention to the comparative analysis of the explant types of vegetatively propagated crops used for the delivery of editing genetic constructs, as well as the comparison of the editing efficiency depending on the variation of the objects used, delivery methods, etc. The article discusses the existing limitations that need to be overcome for a wider application of genomic editing in order to improve varieties of fruit and berry crops, as well as grapes.
\end{abstract}

Keywords: genome editing; CRISPR/Cas9; fruit and berry crops; grape; stress susceptibility; flowering time; plant architectonics; shelf time; plant disease resistance

\section{Introduction}

The UN General Assembly has declared the 2021 year the International Year of Fruits and Vegetables, urging the world community to pay attention to alterations from healthy nutritional norms that have formed due to the excess of food in some regions of the world and their limitations in others [1]. Fruit and berry cultures, such as apples, grapes, bananas, kiwis, pears, strawberries and citruses, are valuable sources of fiber and nutrients that include easily digestible carbohydrates, organic acids, vitamins, micronutrients, antioxidants and other valuable metabolites [2-7] and constitute an integral part of the food culture and modern agricultural industry [8-14].

The quality of modern fruits and berries and their yield and pathogen resistances are the result of long painstaking work through hybridization, progeny characterization and selection. Before the desired phenotype could be selected, a lot of time passes due to a long juvenile period, open pollination and plant heterozygosity waiting for obtaining new stable varieties of perennial fruit and berry cultures in general and woody plants especially. 
Modern breeding methods by means of diagnostic DNA markers usage (markerassisted selection) or genomic selection based on genetic and genomic data (both based on preliminary studies, such as the detailed genetic maps development, NGS-analysis of genomes, transcriptome, microRNome, etc.) have created conditions for rapid and less labor-intensive improvement of fruit properties and the selection of pathogen and pest-resistant varieties [15]. Next-generation breeding methods for genome fruit and berry cultures editing are being intensively developed today [16].

Since the CRISPR/Cas9 system surpasses earlier editing methods (TALEN, ZNFs and meganucleases) in terms of versatility, simplicity and relative cheapness, it has become possible to widely use genetic editing in agriculture [17]. CRISPR/Cas9 is composed of nuclease Cas9 and sgRNA and functions in the form of a ribonucleotide complex: Cas9 recognizes the PAM (protospacer adjacent motif) and cleaves the target sequence to which the sgRNA is complementary to. Nucleases make double-stranded breaks in DNA, which initiate cell repair systems and result in the appearance of deletions or insertions at the site of the break as a result of non-homologous end joining or homology-directed repair mechanisms. If there was a frame shift during the DNA breakage repair, then the gene loses its function [17-19].

CRISPR/Cas9-directed editing gave a unique opportunity for multiplex and polycistronic editing of several targets at the same transformation with relatively high rates [20-22]. This property of the genome editing system is especially valuable for perennial wood plant modifications.

The optimized genome editing techniques provide a unique opportunity to change the properties of commercially viable plant varieties, ensuring their high productivity without the use of redundant treatments with fungicides and pesticides while maintaining the valuable plant variety characteristics. It is hard to overestimate the social, economic and ecological significance of the genome editing techniques for vegetative propagated fruit and berry crops.

Genome editing of first fruit and berry cultures has been conducted by CRISPR/Cas9 fairly recent [23-25]. This review summarizes the results of CRISPR/Cas9 genome editing studies of different groups of target genes in fruit and berry crops: (1) in order to decrease biotic and abiotic stress susceptibility [19,24-39], (2) change flowering time and plant architectonics [40-45], (3) increase shelf-time [46], (4) study gene functions [43-45,47-49] and (5) optimize CRISPR/Cas9 editing of fruit and berry cultures by using the marker $[22,23,32,41,43,44,50-61]$.

\section{Optimization of Editing with Marker Gene Usage}

The primary experiments usually target marker gene with a bright mutant phenotype, which provides an opportunity to determine gene-editing events at early plant shoot growth stage in order to select optimal gene editing conditions [52,58-64] (Table S1).

Gene PDS encodes phytoene desaturase-one of the main carotenoid biosynthesis pathway enzymes that is widely used as a marker for gene editing methods optimization due to bright PDS mutant phenotype, which include albino, variegated or pale-green that depends on mutation pattern of transformed plant. Phytoene desaturase catalyzes desaturation of phytoene to $\zeta$-carotene, which is further converted to lycopene. The components of the carotenoid biosynthetic pathway interact with a variety of cell metabolites such as abscisic acid, strigolactones, gibberilic acid, chlorophyll, plastoquinones and tocopherol, which regulate development and are involved in plant adaptation to environmental changes $[64,65]$. The ability to detect mutant phenotype at the early stages of plant growth for quickly checking the effectiveness of the selected conditions is especially valuable in experiments with perennial crops, which include fruit crops, most berry crops and grapes. This approach, based on the use of the marker gene PDS, has been successfully applied in the optimization of conditions for the CRISPR/Cas9 editing of plants as grapes, apple trees, bananas, strawberries, kiwi and citruses [22,23,32,41,43,44,50-61] (Table S1). 
Using the grape $V v P D S$ marker gene (Vitis vinifera L.), a key parameter for editing frequencies was determined: a high GC content in the guide RNA sequence, which had a greater effect on mutation rate than the Cas9 expression level [58]. Later, the same authors identified and tested promoters $V v U 3, V v U 6$ and $V v U B Q$ for the expression of sgRNA and Cas9, the optimal design schemes for multiplex editing of the grape genome using polycistronic tRNA-gRNA constructions (PTG/Cas9) were selected [53]. The regions adjacent to tRNA are recognized and cut by plant $\mathrm{P}$ and $\mathrm{Z}$ RNases, forming several separate gRNAs, which can direct the nuclease to the different parts of one target gene or to different loci of the genome [22]. In the work of Osakabe et al. a method of non-transgenic edited grapes and apple trees (Malus domestica Borkh.) by means of protoplast transformation with ribonucleoprotein particles (RNP) and the conditions for the regeneration of microcalli of both plant species from the obtained edited protoplasts were selected [52] (Table S1).

The apple tree became the first edited plant from the Rosaceae family. The use of the PDS marker gene revealed the possibility of editing the apple tree genome using shortened gRNAs (18 bp) to obtain a relatively high rate of homozygous mutants $(13.6 \%)$ [23]. Subsequently, PDS usage as an editing marker target gene made it possible to achieve a higher mutation rate (84-90\%) [41]. Zhang et al. have shown that in wild apple (unlike grapes) genome integration rate, mutation rates in both one and two PDS target sites were higher, while gRNA expression was controlled by separate promoters rather than the PTG/Cas9 expression system [61]. Malabarba et al. demonstrated a high degree of chimerism elimination in apple and pear (Pyrus communis L.) shoots with the introduction of an additional stage of transformants regeneration, which may be promising to try on other fruit and berry cultures $[41,50]$ (Table S1).

Naim et al. obtained PDS1 knockout banana plants (Musa accuminata Colla) using a self-cleaving PTG/Cas9 [21,22]. For the expression of Cas9, two CaMV-35S promoters and the promoter of the ubiquitin gene Ubi P were used, which ensured the expression five times higher than with the CaMV-35S promoter. The selected transformants had variegated phenotypes: from albino with a knockout in three alleles to green with insertions/deletions that do not shift the reading frame [22]. Kaur et al. demonstrated the variation in the coding sequences of the PDS gene among different banana cultivars. Kaur's work points to the need for sequencing target genes before planning the editing in order to increase specificity and reduce off-target rate [55]. In Ntui et al. research studies, the genomes of two banana lines $(\mathrm{AAB})$ were edited with a high mutation rate: the usage of gRNAs relative to the conserved PDS region resulted in the absence of off-target editing; 67-94\% of the plants had an albino phenotype due to the editing of all alleles of the PDS gene [56] (Table S1).

A comparison of different genetic constructs was carried out with kiwi fruit (Actinidia deliciosa A. Chev.), and the advantage of using PTG/ Cas9 constructs compared to the standard method using an individual promoter for each gRNA was shown. With PTG/ Cas9 usage, a 10-fold increase in mutation rate was observed due to the tRNA sequence also acting as a transcription enhancer of the RNA polymerase III-initiated promoters. In addition, due to the hydrolysis of a single transcript by RNases and the simultaneous release of two gRNAs in ratios close to equimolar, the authors obtained large deletions: that result was especially valuable for the stable knockout lines selection that will not be able to reverse [60].

Similar results were obtained by Huang et al. on citrus (Citrus $\times$ sinensis (L.) Osbeck), showing a higher PTG/Cas9 constructs efficiency for PDS knockout. As a result, biallelic mutations with a $44.4 \%$ rate and homozygous mutations with a $11.1 \%$ rate were obtained, and the possibility of obtaining large deletions $(15 \mathrm{~kb})$ using CRISPR/Cas9 was demonstrated [32]. Zhu et al. used a marker gene knockout to test editing conditions on another citrus crop kumquat (Fortunella margarita (Lour.) Swingle), comparing the mutation rates, the regeneration of explants and mutations inheritance in the T1 generation. In this work, the kumquat genome was first sequenced and characterized. It was shown that due to the short juvenile period (8 months compared to 5-10 years of other citrus fruits), stable monoembryony and close phylogenetic relationship with other cultivated citrus fruits (es- 
pecially mandarin), kumquat can be successfully used as a model for other plants relative to studying the Citrus genus [59].

The above-mentioned results suggest that the delivery of several gRNAs using PTG/Cas9 vectors is more efficient for genome editing of such fruit and berry crops as grapes and kiwis, unlike apple tree $[21,22,53,60,61]$ (Table S1). Thus, for different fruit and berry crops, the PDS marker gene usage for genome editing experiments made possible both to optimize the gRNA/Cas9 expression and selection/regeneration steps and to change the ratio of chimeric/homozygous plants.

\section{CRISPR/Cas9 for Increasing Disease and Pest Resistance}

One of the most important goals of genome editing is to decrease the susceptibility of crop plants to fungal, viral and bacterial pathogens, which brings not only an obvious economic profit but also contributes to human health and environment.

Gray mold, powdery mildew and downy mildew are the main diseases of grapes, which reduce grape yields and create the need for annual preventive treatments of vineyards with fungicides, which not only spoil the ecology of the regions but also negatively affects the quality of the harvested berries. Downy mildew, powdery mildew and grape gray mold are caused by Plasmopara viticola (Berk. and M.A.Curtis), Berl. and De Toni, Erysiphe necator (Schwein.) and Burrill and Botritis cenerea Fr., respectively. Infection triggers the cell response to biotic stress mechanisms through the ethylene/jasmonate (JA) and the salicylic acid signaling pathways (SA) [66]. In response to biotic stress and in order to limit the spread of infection, a number of expression changes are initiated followed by biochemical and histological alterations in the plant, including the release of phenolic and peroxide compounds and the formation of deposits of callose, papillae and lignin at the site of infection $[66,67]$.

Over the past 20 years, many transgenic grape varieties have been obtained with overexpression of homologous and heterologous components of cell response to biotic stress: pathogen-associated proteins (VvNPR1.1; RCC2; RIP; Chi 11; VpPR4-1; Vvtl-1; VqTLP29; VaTLP; VpPR10.1), antimicrobial peptides (Xenopus laevis Mag2), transcription factors (VvWRKY2; VpWRKY3; VvWRKY33; VvbZIP60; VvDOF3; VvTIFY9; VvZPF11), secondary stress-associated metabolites (Vst1; STS) and genes associated with cell defense (VqJAZ4; pPGIP; nag70; VpEIRP1; VvSNAT2; RPW8.2; VpPUB23; VaPUB; VaHAESA), which were characterized by false mildew and gray mold decreased sensitivity. Nevertheless, the use of these varieties in the industry is associated with additional time and material costs to verify the safety of plant integration into ecosystems and human consumption [68-70]. Due to the safety, speed and low cost for new varieties with pathogen resistance to enter the market, the use of CRISPR/Cas9-mediated genome editing has an undeniable competitive advantage.

Thus, in the work of Wang et al., grape transformants resistant to gray mold were obtained by the WRKY52 gene editing. WRKY52 encodes the transcription factor of the cell's response to biotic stress, a negative regulator of the JA pathway [19]. Later, the same authors have shown high specificity of CRISPR/Cas9 technology for grapevine editing by whole genome sequencing of edited VvWRKY52 and VvbZIP36 T0 plants [39]. VvbZIP36 encodes basic leucine zipper transcription factor, which increases drought tolerance of grape by the regulation of abscisic acid pathway and stress response genes [71]. (Table S1). Grapes are one of the first crops that were modified by direct delivery of guide RNA in ribonucleic acid particles (RNP): This is how regenerants of grapes with the MLO7 gene mutation were obtained, but the mutation rates were quite low $0.1-6.9 \%$ [24]. This technique was improved by Osakabe et al., who managed to obtain a successful protocol for delivery and genome editing using RNP, which takes only 2-3 weeks, while the standard protocol for agrobacterial transformation with a plasmid for CRISPR/Cas9 editing and selection takes 2-3 months [52]. It is assumed that the transmembrane proteins Mlo are the negative regulators of the cell defense mechanisms through vesicular transport and actin cytoskeleton reorganization in response to the biotic stress. MLO-mediated 
powdery mildew resistance is associated with $\mathrm{H}_{2} \mathrm{O}_{2}$ accumulation and host cell death, which result in the formation of papillae and cell wall apposition (CWA) on the MLO mutations' background $[35,72]$ (Table S1). It was shown that grape of the 'Brachetto' variety with the triple knockdown $m l o 7$, mlo6 and $m l o 11$ had a $77 \%$ reduction in susceptibility to powdery mildew [73]. MLO genes mutations often have pleiotropic effects: necrotic leaf spots, accumulation of peroxides and phenolic conjugates on barley, reduced yields and premature senescence of Arabidopsis thaliana, barley and wheat mutants and slow growth of pepper. Nevertheless, in strawberries, apples and grapes, the mutant pleiotropic effects were not described [72-78].

In grapes, Xylella fastidiosa Wells. bacterial infection (XF) (Pierce's desease/ PD) and Red Blotch Disease Viral Infection (GRBV) are accompanied with anthocyanin accumulation regulated through the activity of the MYBA7 transcription factor. The first symptom of GRBV viral disease in grapes is the appearance of red spots on the leaves. The GRBV is carried by sap-sucking insects that develop in the plants' xylem, and as the disease develops in grapes, delayed fruit ripening, acid accumulation and a decrease in the concentration of sucrose and anthocyanins in berries are observed $[27,79]$. The XF pathogenesis in grapes is associated with inorganic phosphate level decrease, the accumulation of anthocyanins and abscisic acid [80]. It is known that phosphate, sugar and ultraviolet light regulate the accumulation of anthocyanins through miR828 and the transacting small interfering RNA locus 4 (TAS4). In grapes, this process is regulated through the formation of small interfering RNAs $T A S 4 a / b / c$, which are differentially expressed and target $M Y B A 5$. Sunitha and Rock selected TAS4 and MYBA7 gene knockout lines [27] (Table S1). The regenerated plants showed no apparent anthocyanins accumulation, possibly due to the presence of repeated loci TAS4c and MYBA5/6 or to the absence of inductive environmental stress conditions. The absence of obvious visible pigment changes in the edited plants made it difficult to test the role of anthocyanins in the mechanisms of resistance/tolerance to PD and GRBV; nevertheless, further study of the transformant shoots seems to be very promising for the selection of PD and GRBV resistant plants. Previously, the inhibition of XF growth by phenolic compounds has been shown, although the level of accumulation of polyphenols in response to infection can vary greatly among different cultivars [81].

Another fruit crop that is losing yield because of diseases is the apple tree. Zhou et al. knocked out the cyclic nucleotide-gated ion gene (CNGC2) and showed the increasing resistance of apple callus cells to the fungal infection Botryosphaeria dothidea (Moug. ex Fr. Ces. and De Not.) and demonstrated a concomitant constitutive increase in salicylic acid (SA) concentration and suppression of $P R$ gene expression. Thus, the authors demonstrated that the protein $\mathrm{CNGC2}$ acted as a negative regulator of $B$. dothidea resistance. At the same time, $C N G C 2$ mutations have some pleiotropic effects and, in addition to resistance to the pathogen, resulted in decrease in fertility, impaired pollen tube formation, and shortened anthers; therefore, as a target for development of pathogen-resistant apple varieties, they are not the optimal choice [29] (Table S1).

For the apple tree, the method of delivering Cas9 and guide RNA in RNP particles was used: the genes DIPM-1, DIPM-2 and DIPM-4, encoding receptor protein kinases, were knocked out [24]. DIPM interacted with the effector protein DspA/E of the bacteria Erwinia amylovora Burrill, which causes bacterial burns of apple and other Rosaceae [82]. Pompili et al. obtained knockout of the MdDIPM-4, while foreign DNA was eliminated from the genome during heat shock by using the FLP/FRT recombination system, which is a promising approach for obtaining edited plants to accelerate and simplify the integration of a successful cultivar into industry [28] (Table S1).

Subtropical banana (Musa L.) and citrus crops (Citrus L.) are other types of fruit crops with great economic importance. In order to make bananas M. accuminata Cavendish (genome AAA) resistant to pathogens, the hybridizations with the diploid bananas M. balbisiana (genome BB) and its derivatives, which are distinguished by their endurance, strong root system and resistance to biotic and abiotic stresses, are used. A significant limitation of hybridization using M. balbisiana and its derivatives is the frequent infection of B-genome plants with 
the banana streak virus (BSV), which results in the plant's death. Tripathy et al., by using the CRISPR/Cas9 editing, introduced mutations in integrative viral elements, making it impossible to transcribe and/or translate functional viral proteins [30,31].

The main pathogen of citruses, which significantly reduces yield, is a bacterial ulcer caused by the pathogen Xanthomonas citri subspecies citri (Xcc). CsLOB1 gene products (LATERAL ORGAN BOUNDARIES 1) are the transcription factors involved in the regulation of plant tissue formation and the main targets for editing and selection of Xcc-resistant citrus fruits [83]. In orange, CsLOB1 is known to have three alleles; the EBEPthA4 regulatory element was found in promoter regions of two of them. EBEPthA4 element is recognized by the main effector $\mathrm{Xcc}$, which results in the CsLOB1 expression activation and triggers the infection. Peng et al. obtained Xcc-resistant plants by knocking out the EBEPthA4 and TATA-box of the CsLOB1 gene in orange [33] (Table S1). Similar results were published earlier on Duncan's grapefruit (Citrus paradisi Macfadyen): The authors demonstrated complete resistance to Xcc in plants biallelic for the LOB1 mutation. The identified heterogeneity of the promoter region in grapefruit, which is a hybrid of a pomelo and an orange, is also interesting [25] (Table S1). The main transcription factors of the citrus immune response to Xcc infection are WRKY22 and WRKY29. The expression level of WRKY22 is significantly different in the sensitive «Newhall» orange variety, which is characterized by a high level of expression of this $\mathrm{TF}$, and in resistant calamondin (Citrus microcarpa) with low levels of expression [84]. Wang et al. obtained an orange with significantly reduced sensitivity relative to Xcc by using CRISPR/Cas9 to obtain chimeric mutants CsWRKY22. The use of different gRNAs showed that there was no correlation between the on-score parameter and editing efficiency, while successful gRNAs had higher GC-content [34] (Table S1). Citrus genomes often contain several allelic variants of target genes; in order to select the optimal scheme for highly efficient editing, it is desirable to sequence the target genes and use several gRNAs [85].

Thus, editing the genome using the CRISPR/Cas9 system is an effective tool for obtaining various fruit crops plants resistant to pathogens; however, the stability of modification and the impact of each mutation on plant metabolism and its varietal characteristics are promising research areas.

\section{Genome Editing for Changing Time of Flowering, Plant Architectonics and Shelf Life of Fruits}

Along with creating pathogen-resistant varieties, genome editing provides an opportunity to change the architectonics of crops, which can improve crop yields and adaptability to environmental changes. For example, Ren et al. used CRISPR/Cas9 editing to knockout the CCD8 gene, which encodes a component of the biosynthesis of strigolactone hormones from carotenoids $[40,86]$. Selected $V v c c d 8$ mutants were characterized by increased shoot branching [40] (Table S1). The weak lodging and high height of banana plants results in significant yield losses in the event of storms and typhoons. The creation of dwarf varieties, without reducing yield and quality of the fruit, can save plantations and crops in unfavorable climatic conditions and simplify the collection of fruits. Mutations in genes encoding the signaling components and gibberellin biosynthetic pathways often have a dwarf phenotype [87]. Shao et al. obtained mutants of the banana cultivar 'Gros Michel' for two genes, Ma04g15900 and Ma08g32850, with reduced height. The Ma04g15900 mutant was characterized by an altered spectrum of gibberellins and an irregular structure of the stratum corneum and epidermal cell layers [42].

The second group of target genes includes potential repressors of flowering and growth of fruit and berry plants. For example, Charrier et al. edited apple and pear plants, knocking out the TFL1 gene encoding the flowering repressor protein (Table S1). The edited plants showed earlier flowering times. Interestingly, for TFL1 editing of both apples and pears, the same gRNA was used [41].

In Varkonyi-Gasic et al. studies on kiwi, a double knockout of AcCEN and AcCEN4 genes, the main candidates of vegetative growth and flowering control, was obtained, which resulted in the production of four kiwi lines, three of which had compact bush shapes 
and early flowering, and one line was characterized only by early flowering. Pollination of these lines resulted in three lines of seeds with 100\% germination [44]. Subsequently, the authors continued to study the influence of the CEN and AcCEN4 genes and the SyGl (Shy Girl) gene on the kiwi dioecy. The authors analyzed the phenotype of F1 plants obtained by self-pollination of the T0 kiwi with CEN4 SyGl double knockout, which gave precocious, small vines. The authors found that $S y G l$ affects the cytokinin profile and was involved in the regulation of cytokinin biosynthesis pathway gene expression. These results indicate that SyGI acts as a suppressor of feminization in kiwifruit and could potentially serve as an accelerator of breeding in outcrossing horticultural woody plants. In addition, this work is one of the few that demonstrates the successful inheritance of the CRISPR/Cas edited genes and the desired traits in F1 perennial woody plants [45].

$\mathrm{Hu}$ et al. have edited banana genome at MA-ACO1 loci, which encodes a key component of the ethylene biosynthetic pathway; the plants were characterized by extended shelf-time $[46,88]$. Six banana lines were selected and analyzed: the edited plants had $15 \%$ smaller size and 5-14\% smaller fruit length and weight. Two of the six lines were planted in the open field, and the time of their full ripening was analyzed. The control line berries have ripened in 21 days, and the edited bananas were still bright yellow upon the 60th day, some with green peel. At the same time, the treatment with the growth regulator ethephon resulted in an almost complete ripening time restoration of edited fruits lines, which is convenient for controlled banana ripening. The fruits obtained from $M A-A C O 1$ edited lines were also characterized by increased content of vitamin C [46] (Table S1).

These studies have shown the high potential of using the CRISPR/Cas9 system to change the flowering time, ripening and shelf life of fruits, as well as to modify the architectonics of the plant in order to reduce losses and render easier crop harvesting.

\section{CRISPR/Cas9-Based Knockout Implementation in Reverse Genetics Studies}

The CRISPR/Cas9 system has become a revolutionary technology in reverse genetics.

Thus, the L-idonate dehydrogenase (VvL-IdnDH), which is involved in the accumulation of tartaric acid (TA) in grape berries and leaves, was studied [51] (Table S1). TA is the main organic acid of grapes, accumulated during the first 4 weeks of ripening. TA is not utilized during fermentation, creates an acidic $\mathrm{pH}$ up to 3-3.5 and determines the resistance of grapes to microorganisms, potentiates ripening and determines the taste of wine and its oxidative characteristics [89] (Table S1). CRISPR/Cas9 was also used for confirmation of the role of GRAS-domain transcription factor VaPAT1 in JA-biosynthesis and cold stress response of grape Vitis amurensis [47]. In grapes, the PR4 gene (pathogenesis-related) was edited, and its role in P. viticola-associated powdery mildew pathogenesis was defined. PR4 encodes chitinase, a chitin-binding protein with DNase activity that inhibits pathogen hyphae growth and has antifungal activity [26] (Table S1).

Strawberries (Fragaria vesca L.) serve as a model object for studying the effect of auxins on fruit development due to the surface localization of seeds on an overgrown floral receptacle. As early as 1950, it was demonstrated that if the ovary is removed after fertilization, the receptacle ceased to develop, but it resumed by means of auxins during the growth of the receptacle. Sequencing of total RNA confirmed the activation of genes of the auxin biosynthesis pathway in achenes after fertilization [90]. It is not surprising that the genes of the auxin biosynthesis pathway were the first genes to be edited in strawberries. Thus, in 2018, the first CRISPR/Cas9 editing work of FveARF8 and FveTAA1 (encode components of the auxins biosynthetic pathway) was published. For the expression of guide RNA, the AtU6-26 and FveU6-2 promoters were used. In the T0 generation, high editing efficiency (49-75\%) was shown, which became even higher in T1 possibly due to the introduction of new mutations in $83 \%$ of the plants by the preserved Cas 9 . Some plants became homozygous at T1, lost Cas9 and had stabilized mutation at T0, which is especially valuable for further safe agricultural industry integration of edited plants. Homozygous FveARF8 mutant plants were characterized by rapid growth and larger size compared to control plants [43]. Another target gene for editing was FveYUC10, which 
encodes a flavin-containing monooxygenase that transforms indole-3-pyruvic acid into indole-3-acetic acid, the main auxin [48,91] (Table S1). Mutant lines were characterized by a $40 \%$ reduced free auxin, but the development and morphology of plants and fruits did not change, which may indicate either functional redundancy of the YUC genes in the F. vesca genome or the existence of a feedback loop or an alternative biosynthesis pathway that can compensate the loss of FveYUC10 [92]. Martín-Pizarro et al. edited, for the first time, the octaploid strawberry for the MADS box gene FaTM6 orthologous to APETALA3 $A$. thaliana. Mutant lines had decreased the amount of reduced pollen and altered flower and anther morphology: short and intense green petals and small and dark anthers. The receptacle did not grow on mutant plant lines, which indicated the key role of FaTM6 in anther development of garden strawberry [93]. The main point that authors managed to demonstrate was the possibility of successfully editing octaploid strawberry by using CRISPR/Cas9.

\section{CRISPR/Cas9 Plant Genomes Editing Limitations and Prospects}

CRISPR/Cas9 genome editing technology has significantly simplified and accelerated the study of gene functions and the process of improving valuable varieties of fruit and berry plants due to the accuracy, speed and low cost; however, the CRISPR/Cas9 editing approach has a number of limitations that are necessary to consider.

First, the following are the limits of the CRISPR/Cas9 system itself.

1. The need for the PAM sequence presence in the target region, which may be absent in the desired genome region. The use of modified Cas9p depending less on the PAM sequence seems to be a promising approach. For example, SpRY nuclease has been tested on monocotyledonous rice and dicotyledonous Dahurian larch (a coniferous tree) [94].

2. The need of gRNA/Cas9 expression optimization for a plant or plant variety, which is especially important for multiplex and polycistronic editing. It is necessary to look for new selective markers because of the duration of plant editing experiments and small number of convenient markers with bright mutant phenotype, which would make possible fast optimization of editing, selection and regeneration steps. The widely used PDS is not a perfect choice: albino mutations result in the death of plant cells, so the mutation frequency, the ratio of their types in a chimeric and heterogeneous cell populations, can be underestimated and is difficult to compare with the frequencies in other studies [54] (Table S1).

3. The heterogeneity of mutations: Editing can occur with the formation of a heterozygous (one mutant allele), biallelic (mutant alleles but different mutations), chimeric (a mixture of different mutation profiles) or homozygous edited plants, with the most desirable homozygous state (all alleles are edited in the same way) that is not often achieved. Plants are often edited with chimeric and biallelic lines formation due to editing with nuclease at different stages of development of the transformed line due to the retention of active nuclease, which indicates the necessity to use inducible rather than constitutive promoters for the expression of nucleases [28,29,33,41,43,48].

4. The limitation of online instruments accuracy: Unfortunately, the results of the selection and analysis of the used gRNAs in different online instruments do not always correlate with each other and with the experimental results (Table S1). To overcome this limitation, it is necessary to use several analysis tools and several gRNAs per target.

5. The Cas9p fidelity: CRISPR/Cas9 predominantly makes indel mutations and is commonly used for gene knockouts. Recently, a series of editors based on CRISPR/Cas9 has been developed, which can perform precise genome manipulation base editing systems for transition or transversion substitutions using a combination of Cas9 nickase and cytidine/adenosine deaminase or Cas9 nickase, cytidine deaminase and uracil-DNAglycosylase, respectively. In addition, technologies for gene prime editing systems using DNA or RNA as donors have been developed [95,96]. Moreover, the use of another accurate nucleases, such as Cpf1p, seems to be rather promising [97]. 
6. The frequent integration of Agrobacterium vector into the plant genome: The need to use an inducible system for the elimination of the vector from the genome in order to obtain a non-transgenic modified plant, for example, FRT / FLP [28].

Second, the limitations of CRISPR/Cas9 delivery systems are as follows.

The use of direct delivery of RNP has significantly reduced the time required for obtaining edited plants; however, unfortunately it did not solve the problem of low mutation rates [52]. The frequency of vector penetration into the cell can be increased by reducing vector size and/or by optimizing the vector capacity. For these purposes, the PTG/Cas 9 systems $[22,32,60,98]$ and self-cleaving linkers $2 \mathrm{~A}[23,52]$ are already commonly used. It may also be promising to use the more compact Cas $\Phi$ nuclease isolated from Biggiephage clade viruses [99] and new delivery vectors such as the recombinant Rhabdovirus. The use of the latter made it possible to obtain single and multiplex editing of the tetraploid tobacco genome without antibiotics selection with a mutation frequency of more than $90 \%$, of which $57 \%$ were tetra-allelic inherited mutations [100].

Third, the selection and regeneration limitations are as follows.

In the vast majority of the reviewed studies, nearly scant information of plant regeneration has been published. It indirectly indicates the need to optimize the stage of plant regeneration in order to increase both the viability of transformants and the frequency of selected homozygous mutated shoots, which can be achieved through alternative selection methods $[50,101-105]$ and the introduction of additional stages of regeneration [50,105].

Finally, the limitations by the biological characteristics of the object of editing are as follows.

Due to the high degree of genome heterozygosity, polyploidy, endoreduplication, chimerism and differences in the metabolism of fruit and berry plants, it is necessary to check the absence of SNPs in the areas of planned editing by sequencing the target gene of the cultivar and select gRNAs in order to the most conservative regions of the gene. It is equally important to assess changes in plant morphology, cell morphology, intracellular structures and key metabolites pattern in order to characterize the pleiotropic effects of the mutation $[56,106,107]$. Nowadays, there are few studies analyzing CRISPR/Cas9 edited T1 lines and F1 perennial fruit and berry plants in general and wood plants in particular. The majority of the published studies characterize transgenic cell mass and T0 plant lines (Table S1). Some of rare examples of characterized edited T1 plants include CCDb4 mutants of mini-citrus kumquat (52) and FveARF8 fast growing mutants of strawberry [43]. It is important to note that all fruit, berry crops and grape are predominantly vegetatively propagated due to long juvenile periods, open pollination, high heterozygosity and concomitant difficulties in stabilization of the valuable trait in the elite background of variety. That is why there are very few examples of F1 generation analysis of CRISPR/Cas9 modified plants: Varkoney-Gasik et al. edited AcCEN4 SyGl, which had resulted in precocious, small vines of kiwi with early flowering that could self-pollinate and produce fast-flowering offspring [45].

\section{Conclusions}

Thus, the effectiveness of CRISPR/Cas9 genome editing of vegetatively propagated fruit and berry crops, as well as grapes, has already been confirmed in a sufficient number of plants (strawberries, grapes, apple trees, pears, kiwi, bananas, oranges, kumquat, grapefruit, etc.), despite the existing methodological limitations that require optimization. Involving more crops in projects for genetic editing of various target genes will optimize existing protocols and, thus, will facilitate the integration of the resulting lines and varieties of fruit and berry crops, as well as grapes, into production.

Supplementary Materials: The following are available online at https:/ / www.mdpi.com/article/10 .3390 /agronomy11091849/s1. 
Author Contributions: Writing—original draft preparation and editing, A.F.; writing-review and editing, N.T., Y.U., E.K. and R.I.; conceptualization and supervision, R.I. and E.K. All authors have read and agreed to the published version of the manuscript.

Funding: The work is supported by the Sirius University of Science and Technology: GNZH-RD-2008.

Institutional Review Board Statement: Not applicable.

Informed Consent Statement: Not applicable.

Acknowledgments: The authors would like to thank Vladimir Smirnov for linguistic assistance.

Conflicts of Interest: The authors have no conflict of interest to declare.

\section{References}

1. United Nations Digital Library Home Page. Available online: http://digitallibrary.un.org/record/3847144/files/A_RES_74_244 -EN.pdf (accessed on 7 January 2020).

2. Copetti, C.; Franco, F.W.; Machado, E.D.R.; Soquetta, M.B.; Quatrin, A.; Ramos, V.M.; Moreira, J.C.F.; Emanuelli, T.; Sautter, C.K.; Penna, N.G. Acute consumption of bordo grape juice and wine improves serum antioxidant status in healthy individuals and inhibits reactive oxygen species production in human neuron-like cells. J. Nutr. Metab. 2018, 2018, 4384012:1-4384012:11. [CrossRef]

3. Toaldo, I.M.; Van Camp, J.; Gonzales, G.B.; Kamiloglu, S.; Bordignon-Luiz, M.T.; Smagghe, G.; Raes, K.; Capanoglu, E.; Grootaert, C. Resveratrol improves TNF- $\alpha$-induced endothelial dysfunction in a coculture model of a Caco-2 with an endothelial cell line. J. Nutr. Biochem. 2016, 36, 21-30. [CrossRef]

4. Barbalho, S.M.; Bueno Ottoboni, A.M.M.; Fiorini, A.M.R.; Guiguer, É.L.; Nicolau, C.C.T.; Goulart, R.A.; Flato, U.A.P. Grape juice or wine: Which is the best option? Crit. Rev. Food Sci. Nutr. 2020, 60, 3876-3889. [CrossRef] [PubMed]

5. Cerezo, A.B.; Labrador, M.; Gutiérrez, A.; Hornedo-Ortega, R.; Troncoso, A.M.; Garcia-Parrilla, M.C. Anti-VEGF Signalling Mechanism in HUVECs by Melatonin, Serotonin, Hydroxytyrosol and Other Bioactive Compounds. Nutrients 2019, $11,2421$. [CrossRef] [PubMed]

6. Singh, B.; Singh, J.P.; Kaur, A.; Singh, N. Bioactive compounds in banana and their associated health benefits-A review. Food Chem. 2016, 206, 1-11. [CrossRef] [PubMed]

7. Falcomer, A.L.; Riquette, R.F.R.; de Lima, B.R.; Ginani, V.C.; Zandonadi, R.P. Health Benefits of Green Banana Consumption: A Systematic Review. Nutrients 2019, 11, 1222. [CrossRef]

8. Song, Y.; Manson, J.E.; Buring, J.E.; Sesso, H.D.; Liu, S. Associations of dietary flavonoids with risk of type 2 diabetes, and markers of insulin resistance and systemic inflammation in women: A prospective study and cross-sectional analysis. J. Am. Coll. Nutr. 2005, 24, 376-384. [CrossRef] [PubMed]

9. Décordé, K.; Teissèdre, P.L.; Auger, C.; Cristol, J.P.; Rouanet, J.M. Phenolics from purple grape, apple, purple grape juice and apple juice prevent early atherosclerosis induced by an atherogenic diet in hamsters. Mol. Nutr. Food Res. 2008, 52, 400-407. [CrossRef]

10. Knekt, P.; Jarvinen, R.; Reunanen, A.; Maatela, J. Flavonoid intake and coronary mortality in Finland: A cohort study. BMJ 1996, 312, 478-481. [CrossRef]

11. Gerhauser, C. Cancer chemopreventive potential of apples, apple juice, and apple components. Planta Med. 2008, 74, 1608-1624. [CrossRef]

12. Barth, S.W.; Fähndrich, C.; Bub, A.; Dietrich, H.; Watzl, B.; Will, F.; Briviba, K.; Rechkemmer, G. Cloudy apple juice decreases DNA damage, hyperproliferation and aberrant crypt foci development in the distal colon of DMH-initiated rats. Carcinogenesis 2005, 26, 1414-1421. [CrossRef]

13. Liu, R.H.; Liu, J.; Chen, B. Apples prevent mammary tumors in rats. J. Agric. Food Chem. 2005, 53, 2341-2343. [CrossRef] [PubMed]

14. Gallus, S.; Talamini, R.; Giacosa, A.; Montella, M.; Ramazzotti, V.; Franceschi, S.; Negri, E.; La Vecchia, C. Does an apple a day keep the oncologist away? Ann. Oncol. 2005, 16, 1841-1844. [CrossRef]

15. Ahmar, S.; Gill, R.A.; Jung, K.H.; Faheem, A.; Qasim, M.U.; Mubeen, M.; Zhou, W. Conventional and Molecular Techniques from Simple Breeding to Speed Breeding in Crop Plants: Recent Advances and Future Outlook. Int. J. Mol. Sci. 2020, 21, 2590. [CrossRef]

16. Tikhonova, N.G.; Khlestkina, E.K. Genetic editing for improvement of fruit and small fruit crops. Hortic. Vitic. 2019, 4, 10-15. [CrossRef]

17. Samanta, M.K.; Dey, A.; Gayen, S. CRISPR/Cas9: An advanced tool for editing plant genomes. Transgen. Res. 2016, 25, 561-573. [CrossRef]

18. Deltcheva, E.; Chylinski, K.; Sharma, C.M.; Gonzales, K.; Chao, Y.; Pirzada, Z.A.; Eckert, M.R.; Vogel, J.; Charpentier, E. CRISPR RNA maturation by trans-encoded small RNA and host factor RNase III. Nature 2011, 471, 602-607. [CrossRef]

19. Wang, X.; Tu, M.; Wang, D.; Liu, J.; Li, Y.; Li, Z.; Wang, Y.; Wang, X. CRISPR/Cas9-mediated efficient targeted mutagenesis in grape in the first generation. Plant Biotechnol. J. 2018, 16, 844-855. [CrossRef]

20. Ma, X.; Zhang, Q.; Zhu, Q.; Liu, W.; Chen, Y.; Qiu, R.; Wang, B.; Yang, Z.; Li, H.; Lin, Y.; et al. A Robust CRISPR/Cas9 System for Convenient, High-Efficiency Multiplex Genome Editing in Monocot and Dicot Plants. Mol. Plant 2015, 8, 1274-1284. [CrossRef]

21. Xie, K.; Minkenberg, B.; Yang, Y. Boosting CRISPR/Cas9 multiplex editing capability with the endogenous tRNA-processing system. Proc. Natl. Acad. Sci. USA 2015, 112, 3570-3575. [CrossRef]

22. Naim, F.; Dugdale, B.; Kleidon, J.; Brinin, A.; Shand, K.; Waterhouse, P.; Dale, J. Gene editing the phytoene desaturase alleles of Cavendish banana using CRISPR/Cas9. Transgen. Res. 2018, 27, 451-460. [CrossRef] 
23. Nishitani, C.; Hirai, N.; Komori, S.; Wada, M.; Okada, K.; Osakabe, K.; Yamamoto, T.; Osakabe, Y. Efficient Genome Editing in Apple Using a CRISPR/Cas9 system. Sci. Rep. 2016, 6, 31481:1-31481:8. [CrossRef]

24. Malnoy, M.; Viola, R.; Jung, M.H.; Koo, O.J.; Kim, S.; Kim, J.S.; Velasco, R.; Nagamangala Kanchiswamy, C. DNA-Free Genetically Edited Grapevine and Apple Protoplast Using CRISPR/Cas9 Ribonucleoproteins. Front. Plant Sci. 2016, 7, 1904:1-1904:9. [CrossRef]

25. Jia, H.; Orbovic, V.; Jones, J.B.; Wang, N. Modification of the PthA4 effector binding elements in Type I CsLOB1 promoter using Cas9/sgRNA to produce transgenic Duncan grapefruit alleviating XccDpthA4:dCsLOB1.3 infection. Plant Biotechnol. J. 2016, 14, 1291-1301. [CrossRef]

26. Li, M.Y.; Jiao, Y.T.; Wang, Y.T.; Zhang, N.; Wang, B.B.; Liu, R.Q.; Yin, X.; Xu, Y.; Liu, G.T. CRISPR/Cas9-mediated VvPR4b editing decreases downy mildew resistance in grapevine (Vitis vinifera L.). Hortic. Res. 2020, 7, 149:1-149:11. [CrossRef] [PubMed]

27. Sunitha, S.; Rock, C.D. CRISPR/Cas9-mediated targeted mutagenesis of TAS4 and MYBA7 loci in grapevine rootstock 101-14. Transgen. Res. 2020, 29, 355-367. [CrossRef] [PubMed]

28. Pompili, V.; Dalla Costa, L.; Piazza, S.; Pindo, M.; Malnoy, M. Reduced fire blight susceptibility in apple cultivars using a high-efficiency CRISPR/Cas9-FLP/FRT-based gene editing system. Plant Biotechnol. J. 2020, 18, 845-858. [CrossRef]

29. Zhou, H.; Bai, S.; Wang, N.; Sun, X.; Zhang, Y.; Zhu, J.; Dong, C. CRISPR/Cas9-Mediated Mutagenesis of MdCNGC2 in Apple Callus and VIGS-Mediated Silencing of MdCNGC2 in Fruits Improve Resistance to Botryosphaeria dothidea. Front. Plant Sci. 2020, 11, 575477:1-575477:11. [CrossRef] [PubMed]

30. Tripathi, J.N.; Ntui, V.O.; Ron, M.; Muiruri, S.K.; Britt, A.; Tripathi, L. CRISPR/Cas9 editing of endogenous banana streak virus in the B genome of Musa spp. overcomes a major challenge in banana breeding. Commun. Biol. 2019, 2, 46:1-46:11. [CrossRef] [PubMed]

31. Tripathi, L.; Ntui, V.O.; Tripathi, J.N. CRISPR/Cas9-based genome editing of banana for disease resistance. Curr. Opin. Plant Biol. 2020, 56, 118-126. [CrossRef]

32. Huang, X.; Wang, Y.; Xu, J.; Wang, N. Development of multiplex genome editing toolkits for citrus with high efficacy in biallelic and homozygous mutations. Plant Mol. Biol. 2020, 104, 297-307. [CrossRef] [PubMed]

33. Peng, A.; Chen, S.; Lei, T.; Xu, L.; He, Y.; Wu, L.; Yao, L.; Zou, X. Engineering canker-resistant plants through CRISPR/Cas9targeted editing of the susceptibility gene CsLOB1 promoter in citrus. Plant Biotechnol. J. 2017, 15, 1509-1519. [CrossRef]

34. Wang, L.; Chen, S.; Peng, A.; Xie, Z.; He, Y.; Zou, X. CRISPR/Cas9-mediated editing of CsWRKY22 reduces susceptibility to Xanthomonas citri subsp. citri in Wanjincheng orange (Citrus sinensis (L.) Osbeck). Plant Biotechnol. Rep. 2019, 13, 501-510. [CrossRef]

35. Wan, D.Y.; Guo, Y.; Cheng, Y.; Hu, Y.; Xiao, S.; Wang, Y.; Wen, Y.Q. CRISPR/Cas9-mediated mutagenesis of VvMLO3 results in enhanced resistance to powdery mildew in grapevine (Vitis vinifera). Hortic. Res. 2020, 7, 116:1-116:14. [CrossRef] [PubMed]

36. Jia, H.; Omar, A.; Orbović, V.; Wang, N. Biallelic editing of the LOB1 promoter via CRISPR/Cas9 creates canker-resistant 'Duncan' grapefruit. Phytopathology 2021. [CrossRef] [PubMed]

37. Tripathi, J.N.; Ntui, V.O.; Shah, T.; Tripathi, L. CRISPR/Cas9-mediated editing of DMR6 orthologue in banana (Musa spp.) confers enhanced resistance to bacterial disease. Plant Biotechnol. J. 2021, 19, 1291-1293. [CrossRef]

38. Tripathi, L.; Ntui, V.O.; Tripathi, J.N.; Kumar, P.L. Application of CRISPR/Cas for Diagnosis and Management of Viral Diseases of Banana. Front. Microbiol. 2021, 11, 609784:1-609784:13. [CrossRef] [PubMed]

39. Wang, X.; Tu, M.; Wang, Y.; Yin, W.; Zhang, Y.; Wu, H.; Gu, Y.; Li, Z.; Xi, Z.; Wang, X. Whole-genome sequencing reveals rare off-target mutations in CRISPR/Cas9-edited grapevine. Hortic. Res. 2021, 8, 114:1-114:11. [CrossRef]

40. Ren, C.; Guo, Y.; Kong, J.; Lecourieux, F.; Dai, Z.; Li, S.; Liang, Z. Knockout of VvCCD8 gene in grapevine affects shoot branching. BMC Plant Biol. 2020, 20, 47:1-47:8. [CrossRef]

41. Charrier, A.; Vergne, E.; Dousset, N.; Richer, A.; Petiteau, A.; Chevreau, E. Efficient Targeted Mutagenesis in Apple and First Time Edition of Pear Using the CRISPR-Cas9 System. Front. Plant Sci. 2019, 10, 40:1-40:12. [CrossRef]

42. Shao, X.; Wu, S.; Dou, T.; Zhu, H.; Hu, C.; Huo, H.; He, W.; Deng, G.; Sheng, O.; Bi, F.; et al. Using CRISPR/Cas9 genome editing system to create MaGA20ox2 gene-modified semi-dwarf banana. Plant Biotechnol. J. 2020, 18, 17-19. [CrossRef] [PubMed]

43. Zhou, J.; Wang, G.; Liu, Z. Efficient genome-editing of wild strawberry genes, vector development, and validation. Plant Biotechnol. J. 2018, 16, 1868-1877. [CrossRef]

44. Varkonyi-Gasic, E.; Wang, T.; Voogd, C.; Jeon, S.; Drummond, R.S.M.; Gleave, A.P.; Allan, A.C. Mutagenesis of kiwifruit CENTRORADIALIS-like genes transforms a climbing woody perennial with long juvenility and axillary flowering into a compact plant with rapid terminal flowering. Plant Biotechnol. J. 2019, 17, 869-880. [CrossRef]

45. Varkonyi-Gasic, E.; Wang, T.; Cooney, J.; Jeon, S.; Voogd, C.; Douglas, M.J.; Pilkington, S.M.; Akagi, T.; Allan, A.C. Shy Girl, a kiwifruit suppressor of feminization, restricts gynoecium development via regulation of cytokinin metabolism and signalling. New Phytol. 2021, 230, 1461-1475. [CrossRef] [PubMed]

46. Hu, C.; Sheng, O.; Deng, G.; He, W.; Dong, T.; Yang, Q.; Dou, T.; Li, C.; Gao, H.; Liu, S.; et al. CRISPR/Cas9-mediated Genome Editing of MaACO1 (aminocyclopropane-1-carboxylate oxidase1) Promotes the Shelf Life of Banana Fruit. Plant Biotechnol. J. 2021, 19, 654-656. [CrossRef] [PubMed]

47. Wang, Z.; Wong, D.C.J.; Wang, Y.; Xu, G.; Ren, C.; Liu, Y.; Kuang, Y.; Fan, P.; Li, S.; Xin, H.; et al. GRAS-domain transcription factor PAT1 regulates jasmonic acid biosynthesis in grape cold stress response. Plant Physiol. 2021, 186, 1660-1678. [CrossRef] [PubMed]

48. Feng, J.; Dai, C.; Luo, H.; Han, Y.; Liu, Z.; Kang, C. Reporter gene expression reveals precise auxin synthesis sites during fruit and root development in the wild strawberry. J. Exp. Bot. 2019, 70, 563-574. [CrossRef]

49. Martin-Pizarro, C.; Trivino, J.C.; Pose, D. Functional analysis of TM6 MADS-box gene in the octoploid strawberry by CRISPR/Cas9 directed mutagenesis. J. Exp. Bot. 2018, 70, 885-895. [CrossRef] 
50. Malabarba, J.; Chevreau, E.; Dousset, N.; Veillet, F.; Moizan, J.; Vergne, E. New Strategies to Overcome Present CRISPR/Cas9 Limitations in Apple and Pear: Efficient Dechimerization and Base Editing. Int. J. Mol. Sci. 2020, 22, 319. [CrossRef]

51. Ren, C.; Liu, X.; Zhang, Z.; Wang, Y.; Duan, W.; Li, S.; Liang, Z. CRISPR/ Cas9-mediated efficient targeted mutagenesis in Chardonnay (Vitis vinifera L.). Sci. Rep. 2016, 6, 32289:1-32289:9. [CrossRef]

52. Osakabe, Y.; Liang, Z.; Ren, C.; Nishitani, C.; Osakabe, K.; Wada, M.; Komori, S.; Malnoy, M.; Velasco, R.; Poli, M.; et al. CRISPR-Cas9-mediated genome editing in apple and grapevine. Nat. Protoc. 2018, 13, 2844-2863. [CrossRef]

53. Ren, C.; Liu, Y.; Guo, Y.; Duan, W.; Fan, P.; Li, S.; Liang, Z. Optimizing the CRISPR/Cas9 system for genome editing in grape by using grape promoters. Hortic. Res. 2021, 8, 52:1-52:12. [CrossRef]

54. Nakajima, I.; Ban, Y.; Azuma, A.; Onoue, N.; Moriguchi, T.; Yamamoto, T.; Toki, S.; Endo, M. CRISPR/Cas9-mediated targeted mutagenesis in grape. PLoS ONE 2017, 12, 0177966:1-0177966:16. [CrossRef] [PubMed]

55. Kaur, N.; Alok, A.; Shivani; Kaur, N.; Pandey, P.; Awasthi, P.; Tiwari, S. CRISPR/Cas9-mediated efficient editing in phytoene desaturase (PDS) demonstrates precise manipulation in banana cv. Rasthali genome. Funct. Integr. Genom. 2018, 18, 89-99. [CrossRef]

56. Ntui, V.O.; Tripathi, J.N.; Tripathi, L. Robust CRISPR/Cas9 mediated genome editing tool for banana and plantain (Musa spp.). Curr. Plant Biol. 2020, 21, 100128:1-100128:10. [CrossRef]

57. Dutt, M.; Mou, Z.; Zhang, X.; Tanwir, S.E.; Grosser, J.W. Efficient CRISPR/Cas9 genome editing with Citrus embryogenic cell cultures. BMC Biotechnol. 2020, 20, 58:1-58:7. [CrossRef]

58. Ren, F.; Ren, C.; Zhang, Z.; Duan, W.; Lecourieux, D.; Li, S.; Liang, Z. Efficiency Optimization of CRISPR/Cas9-Mediated Targeted Mutagenesis in Grape. Front. Plant Sci. 2019, 10, 612:1-612:9. [CrossRef]

59. Zhu, C.; Zheng, X.; Huang, Y.; Ye, J.; Chen, P.; Zhang, C.; Zhao, F.; Xie, Z.; Zhang, S.; Wang, N.; et al. Genome sequencing and CRISPR/Cas9 gene editing of an early flowering Mini-Citrus (Fortunella hindsii). Plant Biotechnol. J. 2019, 17, 2199-2210. [CrossRef]

60. Wang, Z.; Wang, S.; Li, D.; Zhang, Q.; Li, L.; Zhong, C.; Liu, Y.; Huang, H. Optimized paired-sgRNA/Cas9 cloning and expression cassette triggers high-efficiency multiplex genome editing in kiwifruit. Plant Biotechnol. J. 2018, 16, 1424-1433. [CrossRef]

61. Zhang, Y.; Zhou, P.; Bozorov, T.A.; Zhang, D. Application of CRISPR/Cas9 technology in wild apple (Malus sieverii) for paired sites gene editing. Plant Methods 2021, 17, 79:1-79:9. [CrossRef]

62. Qin, G.; Gu, H.; Ma, L.; Peng, Y.; Deng, X.W.; Chen, Z.; Qu, L.J. Disruption of phytoene desaturase gene results in albino and dwarf phenotypes in Arabidopsis by impairing chlorophyll, carotenoid, and gibberellin biosynthesis. Cell Res. 2007, 17, 471-482. [CrossRef]

63. Xie, X.; Yoneyama, K.; Yoneyama, K. The strigolactone story. Annu. Rev. Phytopathol. 2010, 48, 93-117. [CrossRef]

64. Hou, X.; Rivers, J.; León, P.; McQuinn, R.P.; Pogson, B.J. Synthesis and Function of Apocarotenoid Signals in Plants. Trends Plant Sci. 2016, 21, 792-803. [CrossRef]

65. Cazzonelli, C.I.; Pogson, B.J. Source to sink: Regulation of carotenoid biosynthesis in plants. Trends Plant Sci. 2010, 15, 266-274. [CrossRef]

66. Caarls, L.; Pieterse, C.M.; Van Wees, S.C. How salicylic acid takes transcriptional control over jasmonic acid signaling. Front. Plant Sci. 2015, 6, 170:1-170:11. [CrossRef]

67. Bai, C.; Capell, T.; Berman, J.; Medina, V.; Sandmann, G.; Christou, P.; Zhu, C. Bottlenecks in carotenoid biosynthesis and accumulation in rice endosperm are influenced by the precursor-product balance. Plant Biotechnol. J. 2016, 14, 195-205. [CrossRef] [PubMed]

68. Capriotti, L.; Baraldi, E.; Mezzetti, B.; Limera, C.; Sabbadini, S. Biotechnological Approaches: Gene Overexpression, Gene Silencing, and Genome Editing to Control Fungal and Oomycete Diseases in Grapevine. Int. J. Mol. Sci. 2020, 21, 5701. [CrossRef] [PubMed]

69. Yang, S.; Shi, Y.; Zou, L.; Huang, J.; Shen, L.; Wang, Y.; Guan, D.; He, S. Pepper CaMLO6 Negatively Regulates Ralstonia solanacearum Resistance and Positively Regulates High Temperature and High Humidity Responses. Plant Cell Physiol. 2020, 61, 1223-1238. [CrossRef]

70. Hartung, F.; Schiemann, J. Precise plant breeding using new genome editing techniques: Opportunities, safety and regulation in the EU. Plant J. 2014, 78, 742-752. [CrossRef] [PubMed]

71. Tu, M.; Wang, X.; Feng, T.; Sun, X.; Wang, Y.; Huang, L.; Gao, M.; Wang, Y.; Wang, X. Expression of a grape (Vitis vinifera) bZIP transcription factor, VlbZIP36, in Arabidopsis thaliana confers tolerance of drought stress during seed germination and seedling establishment. Plant Sci. 2016, 252, 311-323. [CrossRef] [PubMed]

72. Consonni, C.; Humphry, M.E.; Hartmann, H.A.; Livaja, M.; Durner, J.; Westphal, L.; Vogel, J.; Lipka, V.; Kemmerling, B.; Schulze-Lefert, P.; et al. Conserved requirement for a plant host cell protein in powdery mildew pathogenesis. Nat. Genet. 2006, 38, 716-720. [CrossRef]

73. Pessina, S.; Lenzi, L.; Perazzolli, M.; Campa, M.; Dalla Costa, L.; Urso, S.; Valè, G.; Salamini, F.; Velasco, R.; Malnoy, M. Knockdown of $M L O$ genes reduces susceptibility to powdery mildew in grapevine. Hortic. Res. 2016, 3, 16016:1-16016:9. [CrossRef]

74. Zheng, Z.; Nonomura, T.; Appiano, M.; Pavan, S.; Matsuda, Y.; Toyoda, H.; Wolters, A.M.; Visser, R.G.; Bai, Y. Loss of function in Mlo orthologs reduces susceptibility of pepper and tomato to powdery mildew disease caused by Leveillula taurica. PLoS ONE 2013, 8, e70723:1-e70723:14. [CrossRef] [PubMed]

75. Wang, Y.; Cheng, X.; Shan, Q.; Zhang, Y.; Liu, J.; Gao, C.; Qiu, J.L. Simultaneous editing of three homoeoalleles in hexaploid bread wheat confers heritable resistance to powdery mildew. Nat. Biotechnol. 2014, 32, 947-951. [CrossRef]

76. von Röpenack, E.; Parr, A.; Schulze-Lefert, P. Structural analyses and dynamics of soluble and cell wall-bound phenolics in a broad spectrum resistance to the powdery mildew fungus in barley. J. Biol. Chem. 1998, 273, 9013-9022. [CrossRef]

77. Jiwan, D.; Roalson, E.H.; Main, D.; Dhingra, A. Antisense expression of peach mildew resistance locus O (PpMlo1) gene confers cross-species resistance to powdery mildew in Fragaria $x$ ananassa. Transgen. Res. 2013, 22, 1119-1131. [CrossRef] [PubMed] 
78. Pessina, S.; Angeli, D.; Martens, S.; Visser, R.G.; Bai, Y.; Salamini, F.; Velasco, R.; Schouten, H.J.; Malnoy, M. The knock-down of the expression of MdMLO19 reduces susceptibility to powdery mildew (Podosphaera leucotricha) in apple (Malus domestica). Plant Biotechnol. J. 2016, 14, 2033-2044. [CrossRef]

79. Johnson, K.B. Pathogen refuge: A key to understanding biological control. Annu. Rev. Phytopathol. 2010, 48, 141-160. [CrossRef]

80. Lin, H.; Doddapaneni, H.; Takahashi, Y.; Walker, M.A. Comparative analysis of ESTs involved in grape responses to Xylella fastidiosa infection. BMC Plant Biol. 2007, 7, 8:1-8:13. [CrossRef]

81. Maddox, C.E.; Laur, L.M.; Tian, L. Antibacterial activity of phenolic compounds against the phytopathogen Xylella fastidiosa. Curr. Microbiol. 2010, 60, 53-58. [CrossRef] [PubMed]

82. Siamer, S.; Guillas, I.; Shimobayashi, M.; Kunz, C.; Hall, M.N.; Barny, M.A. Expression of the bacterial type III effector DspA/E in Saccharomyces cerevisiae down-regulates the sphingolipid biosynthetic pathway leading to growth arrest. J. Biol. Chem. 2014, 289, 18466-18477. [CrossRef]

83. Hu, Y.; Zhang, J.L.; Jia, H.G.; Sosso, D.; Li, T.; Frommer, W.B.; Yang, B.; White, F.F.; Wang, N.; Jones, J.B. Lateral organ boundaries 1 is a disease susceptibility gene for citrus bacterial canker disease. Proc. Natl. Acad. Sci. USA 2014, 111, 521-529. [CrossRef]

84. Zhou, P.; Jia, R.; Chen, S.; Xu, L. Cloning and Expression Analysis of Four Citrus WRKY Genes Responding to Xanthomon asaxonopodis pv. citri. Acta Hortic. Sin. 2017, 44, 452-462. [CrossRef]

85. Oh, Y.; Lee, B.; Kim, H.; Kim, S.G. A multiplex guide RNA expression system and its efficacy for plant genome engineering. Plant Methods 2020, 16, 37:1-37:11. [CrossRef]

86. Booker, J.; Auldridge, M.; Wills, S.; McCarty, D.; Klee, H.; Leyser, O. MAX3/CCD7 is a carotenoid cleavage dioxygenase required for the synthesis of a novel plant signaling molecule. Curr. Biol. 2004, 14, 1232-1238. [CrossRef] [PubMed]

87. Chen, J.; Xie, J.; Duan, Y.; Hu, H.; Hu, Y.; Li, W. Genome-wide identification and expression profiling reveal tissue-specific expression and differentially-regulated genes involved in gibberellin metabolism between Williams banana and its dwarf mutant. BMC Plant Biol. 2016, 16, 123:1-123:18. [CrossRef] [PubMed]

88. Inaba, A.; Liu, X.; Yokotani, N.; Yamane, M.; Lu, W.J.; Nakano, R.; Kubo, Y. Differential feedback regulation of ethylene biosynthesis in pulp and peel tissues of banana fruit. J. Exp. Bot. 2007, 58, 1047-1057. [CrossRef] [PubMed]

89. Wen, Y.Q.; Li, J.M.; Zhang, Z.Z.; Zhang, Y.F.; Pan, Q.H. Antibody preparation, gene expression and subcellular localization of L-idonate dehydrogenase in grape berry. Biosci. Biotechnol. Biochem. 2010, 74, 2413-2417. [CrossRef]

90. Kang, C.; Liu, Z. Global identification and analysis of long non-coding RNAs in diploid strawberry Fragaria vesca during flower and fruit development. BMC Genom. 2015, 16, 815:1-815:15. [CrossRef]

91. Stepanova, A.N.; Yun, J.; Robles, L.M.; Novak, O.; He, W.; Guo, H.; Ljung, K.; Alonso, J.M. The Arabidopsis YUCCA1 flavin monooxygenase functions in the indole-3-pyruvic acid branch of auxin biosynthesis. Plant Cell 2011, 23, 3961-3973. [CrossRef]

92. Tivendale, N.D.; Ross, J.J.; Cohen, J.D. The shifting paradigms of auxin biosynthesis. Trends Plant Sci. 2014, 19, 44-51. [CrossRef] [PubMed]

93. Martín-Pizarro, C.; Posé, D. Genome Editing as a Tool for Fruit Ripening Manipulation. Front. Plant Sci. 2018, 9, 1415:1-1415:8. [CrossRef] [PubMed]

94. Ren, Q.; Sretenovic, S.; Liu, S.; Tang, X.; Huang, L.; He, Y.; Liu, L.; Guo, Y.; Zhong, Z.; Liu, G.; et al. PAM-less plant genome editing using a CRISPR-SpRY toolbox. Nat. Plants 2021, 7, 25-33. [CrossRef]

95. Zhu, H.; Li, C.; Gao, C. Applications of CRISPR-Cas in agriculture and plant biotechnology. Nat. Rev. Mol. Cell Biol. 2020, 21, 661-677. [CrossRef]

96. Sukegawa, S.; Saika, H.; Toki, S. Plant genome editing: Ever more precise and wide reaching. Plant J. 2021, 106, 1208-1218. [CrossRef] [PubMed]

97. Gerashchenkov, G.A.; Rozhnova, N.A.; Kuluev, B.R.; Kiryanova, O.Y.; Gumerova, G.R.; Knyazev, A.V.; Vershinina, Z.R.; Mikhailova, E.V.; Chemeris, D.A.; Matniyazov, R.T.; et al. Design of Guide RNA for CRISPR/Cas Plant Genome Editing. Mol. Biol. 2020, 54, 29-50. [CrossRef]

98. Gao, Y.; Zhao, Y. Self-processing of ribozyme-flanked RNAs into guide RNAs in vitro and in vivo for CRISPR-mediated genome editing. J. Integr. Plant Biol. 2014, 56, 343-349. [CrossRef]

99. Pausch, P.; Al-Shayeb, B.; Bisom-Rapp, E.; Tsuchida, C.A.; Li, Z.; Cress, B.F.; Knott, G.J.; Jacobsen, S.E.; Banfield, J.F.; Doudna, J.A CRISPR-Cas $\Phi$ from huge phages is a hypercompact genome editor. Science 2020, 369, 6501:333-6501:337. [CrossRef]

100. Ma, X.; Zhang, X.; Liu, H.; Li, Z. Highly efficient DNA-free plant genome editing using virally delivered CRISPR-Cas9. Nat. Plants 2020, 6, 773-779. [CrossRef]

101. Cai, W.; Gonsalves, C.; Tennant, P.; Fermin, G.; Souza, M.; Sarindu, N.; Jan, F.J.; ZHU, H.Y.; Gonsalves, D. A protocol for efficient transformation and regeneration of Carica papaya L. In Vitro Cell. Dev. Biol._Plant 1999, 35, 61:1-61:9. [CrossRef]

102. Dhekney, S.A.; Sessions, S.K.; Brungart-Rosenberg, M.; Claflin, C.; Li, Z.T.; Gray, D.J. Genetic Modification of Grapevine Embryogenic Cultures. In Transgenic Plants: Methods and Protocols, Methods in Molecular Biology; Kumar, S., Barone, P., Smith, M., Eds.; Humana Press: New York, NY, USA, 2019; Volume 1864, pp. 191-202. [CrossRef]

103. Kandel, R.; Bergey, D.R.; Dutt, M.; Sitther, V.; Li, Z.T.; Gray, D.J.; Dhenkey, S.A. Evaluation of a grapevine-derived reporter gene system for precision breeding of Vitis. Plant Cell Tissue Organ Cult. 2016, 124, 599-609. [CrossRef]

104. Zhu, L.H.; Li, X.Y.; Ahlman, A.; Xue, Z.T.; Welander, M. The use of mannose as a selection agent in transformation of the apple rootstock m26 via Agrobacterium tumefaciens. Acta Hortic. 2004, 663, 503-506. [CrossRef]

105. Malnoy, M.; Boresjza-Wysocka, E.E.; John, L.; Norelli, J.L.; Flaishman, M.A.; Gidoni, D.; Aldwinckle, H.S. Genetic transformation of apple (Malus $\times$ domestica) without use of a selectable marker gene. Tree Genet. Genomes 2010, 6, 423-433. [CrossRef] 
106. Hückelhoven, R. The effective papilla hypothesis. New Phytol. 2014, 204, 438-440. [CrossRef]

107. Bouquet, A.; Torregrosa, L.; Iocco, P.; Thomas, M.R. Grapevine (Vitis vinifera L.). Methods Mol. Biol. 2006, 344, 273-285. [CrossRef] [PubMed] 